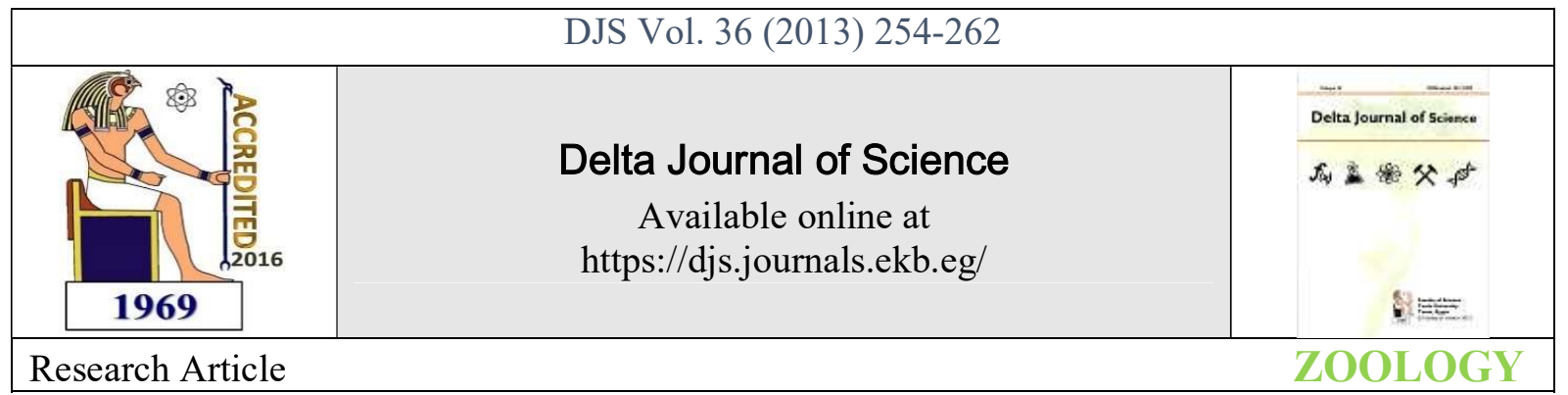

\title{
Effect of low concentrations of two plant extracts on the spermatozoon ultrastructure of three snail species.
}

\author{
Mohammed F.A. Mansour, Sayed-Ahmed M. El-Tantawy and Heba M. Fala \\ Zoology Department, Faculty of Science, Mansoura University, Egypt. \\ Keywords: Calotropis procera, Pelargonium graveolens, Ethulia conyzoides Euphorbia milii, , \\ Lymnaea caillaudi, Biomphalaria alexandrina, Eobania vermiculata
}

\begin{abstract}
The present study deals for the first time the effect of two plant extracts on the ultrastructure of the spermatozoa of three species of gastropod snails. These snails were the land snail Eobania vermiculata and two freshwater ones Lymnaea caillaudi and Biomphalaria alexandrina. They were collected from gardens and fruit trees (E. vermiculata) and Manzala Lake (L. caillaudi and B. alexandrina), Dakahlia Governorate, Egypt. The extracts used were of the plants Euphorbia milii and Ethulia coynzoides. The first was used for L. caillaudi and B. alexandrina and the second was used for E. vermiculata.

The snails used for this purpose were those still alive after the exposure period to the plant extracts (28 dayes for E. vermiculata and $24 \mathrm{~h}$ for L. caillaudi and B. alexandrina). Examination of the longitudinal and transverse thin sections revealed that the genital cells gonadal follicles and the head and the neck region of the sperm were the most affected ones. This indicates that these snails become nearly sterile where the gonads become unable to produce spermatozoa or the liberated sperms become immotile having damaged mitochondrial derivatives and loose their viability. This effect on sperms can be considered as a new way to control the injurious snails to agriculture and can bring their population down to a low level within a reasonably short period of time.
\end{abstract}

\section{Materials and Methods}

\section{INTRODUCTION}

Snail control may be achieved by physical (McCullough, 1986), chemical (Masola et al., 2003), and biological methods, (Kloos et al., 2001; Rashed, 2002), Chemical control by molluscicides is performed by using different compounds (Essawy et al., 2009; Kristoff et al., 2010). However, high costs of chemical molluscicides, the possible built up of snail resistance to molluscicides and their toxicity to non target organisms has drawn much attention during recent years for the use of plant molluscicides. As reported by several investigators, these represent cheap, safe, locally produced, biodegradable and effective agents in rural areas of developing countries where schistosomiasis is endemic (AlDaihan, 2010). Plants with molluscicidal action and their standardization, recommended by the WHO, emphasises placed on the use of products with high snail mortality at low doses. Therefore the search for alternative molluscicides is still ongoing. In Egypt, screening of local plants for molluscicidal activity has received increasing attention, several local plant species screened and proved to have molluscicidal properties against different snail species.

\section{Collection of the Snails}

Adult snails with a similar shell size of the land snail, Eobania vermiculata (Müller), freshwater snails Lymnaea caillaudi and Biomphalaria alexandrina were collected from Dakahlia, Governorate, Egypt and stored for two weeks in

20L dechlorinated tap water for patent trematode infections and also acclimatization under laboratory condition before the treatments with the plant extracts. The snails were dissected to separate their gonads to examine their mature spermatozoa after their treatments with LC25 of the two plant extracts (Ethulia conyzoides \& Euphorbia milii) with the highest mortality rate. Immediately after dissection, small pieces of gonads of the selected species (Eobania vermiculata, Lymnaea caillaudi and Biomphalaria alexandrina) were placed separately in freshly prepared $2.5 \%$ cold glutaraldehyde buffered in $0.1 \mathrm{M}$ sodium cacodylate buffer with $\mathrm{pH} 7.2$ at $4 \mathrm{oC}$ and rinsed overnight in the buffer at $4 \mathrm{oC}$. The specimens were post-fixed in $1 \%$ cold osmium tetra-oxide buffered in 0.1 $\mathrm{M}$ sodium cacodylate at $\mathrm{pH} 7.2$ for $3 \mathrm{~h}$. Then, they were dehydrated through ascending grades of ethanol and embedded in resin. Ultrathin sections were stained in uranyl 
acetate and lead citrate and examined using JEOL $100 \mathrm{CX}$ electron microscope, in Electron Microscope Unit at the Faculty of Science, Alexandria University, Egypt.

\section{RESULTS}

Table (1) represents the LC25 values of the four plant extracts used for the treatments of the snails to study their effect on the ultrastructure of the snails mature spermatozoon. From the table it was clear according to LC25 that E. conyzoides was the most effective on the land snail Eobania vermiculata than the other used extracts (1795.781ppm). Moreover, E. milii was the most active on the freshwater snails Lymnaea caillaudi and Biomphalaria alexandrina, where LC25 was 4.688 ppm and $9.546 \mathrm{ppm}$ respectively.

Table (1): Shows the LC25 of the four plant extracts on the three pulmonate snail species used for farther investigations.

\begin{tabular}{|c|c|c|c|c|}
\hline \multirow{2}{*}{ Snail species } & \multicolumn{4}{|c|}{ Plant extracts } \\
\cline { 2 - 5 } & $\begin{array}{c}\text { Calotropis } \\
\text { procera }\end{array}$ & $\begin{array}{c}\text { Pelargonium } \\
\text { graveolens }\end{array}$ & $\begin{array}{c}\text { Ethulia } \\
\text { conyzoides }\end{array}$ & $\begin{array}{c}\text { Euphorbia } \\
\text { milii }\end{array}$ \\
\hline $\begin{array}{c}\text { Biomphalaria } \\
\text { alexandrina }\end{array}$ & 20.049 & 43.075 & 21.411 & 9.546 \\
\hline $\begin{array}{c}\text { Lymnaea } \\
\text { caillaudi }\end{array}$ & 32.363 & 14.085 & 9.287 & 4.702 \\
\hline $\begin{array}{c}\text { Eobania } \\
\text { vermiculata }\end{array}$ & 3543.269 & 2797.055 & 1795.781 & - \\
\hline
\end{tabular}

- Not effective.

\section{Spermatozoa ultrastructure}

Effect of Ethulia conyzoides plant extract on the spermatozoon ultrastructure of Eobania vermiculata

Examination of the longitudinal and transverse sections revealed that the genital cells of gonadal follicles were the most affected ones (Fig. 1) Leading to a high decrease in the number of the spermatozoa. The few spermatozoa which were detected inside the follicles of gonads revealed that the most affected parts of them were the head region (Fig. 2). The nucleus has deformities in the chromatin material and the presence of some vacuoles. Also, the posterior region of the nucleus appeared without nuclear fossa. The neck region appeared as a small lighter part without presence of any centriolar derivatives or other structures (Fig. 2). On the other hand, posterior to the neck region the midpiece was normal in structure where the single glycogen helix was well developed and not affected by the plant extract. The axoneme was also normal surrounded by the paracrystalline layers. The mitochondrial matrix was not differentiated (Figs. 2-6).

Effect of Euphorbia milii plant extract on the spermatozoon ultrastructure of Lymnaea caillaudi

After treatment of the snail L. caillaudi by the extract of Euphorbia milii and by the examination of the transverse and longitudinal sections of the spermatozoa, the sperm ultrastructure was highly affected (Figs. 7-14).

The head: The acrosome was not detected in the sections examined. The nucleus appeared transversely circular surrounded with a loosely damaged plasma membrane. The nuclear material or chromatin becomes lighter than the normal one and appeared damaged where there were many dark electron-dense pieces scattered irregularly inside the nucleus (Figs. 7-9). The nuclear keels in the normal nucleus of this species were absent in the treated one as they were damaged.

The midpiece: The neck region was not detected. In the glycogen helix region, the helices were abnormal, where they are absent in some parts (Figs. 11\&12) or present as small ones with few or without glycogen granules (Figs. 9,10\&14). In some spermatozoa as revealed in few sections 6 or 7 helices appeared but smaller in size than the normal and with or without glycogen granules (Fig. 9). Generally, as revealed from the longitudinal sections the glycogen helices have a great deformities as they appeared as a lateral swellings allover the midpiece (Figs. 13\&14). It seems that the axoneme is affected in the anterior half of the midpiece (Figs. 10-12) than in its posterior half (Fig. 9). The mitochondrial derivatives were found surrounding the axoneme but its layers were not differentiated and the mitochondrial matrix was absent (Figs. 9-12).

Effect of Euphorbia milii plant extract on the spermatozoon ultrastructure of Biomphalaria alexandrina

The examination of the longitudinal and transverse sections of the spermatozoon of $B$. alexandrina revealed that there is an obvious effect on its ultrastructure (Figs. 15-22).

The head: The acrosome is not detected. The nucleus revealed highly demarcated changes. The plasma membrane is absent or not observed (Figs. 15,16\&18) the nuclear shape is irregular (Figs. 16\&18) the chromatin material seems to be lighter in colour and generally vacuolated. The vacuoles are not empty but contain more lighter nuclear material (Figs.16\&18). In many cases, the nucleus becomes swollen and largely elongated (Figs. 17,18,19,21\&22).

The neck: Mostly this region seems to be damaged, but in some spermatozoa it is weakly identified with a small damaged centriolar derivatives and coarse fibers. The central axonemal microtubules in this region are not observed (Fig. 15).

The glvcogen helix region: In comparison with the normal spermatozoon of this species, as there were four glycogen helices, it was noticed that the treated spermatozoon has obvious effects and changes in this region. As the helices start in the neck region, they become absent (Fig. 15). Posterior to the neck region the glycogen helices appear reduced in size and irregular in number allover the midpiece region (Figs. 15-21). With respect to the mitochondrial derivatives, it was noticed that the Paracrystalline material was damaged and became a homogeneous material, not differentiated into layers. Also, the mitochondrial matrix is darkly found but irregularly surrounding the axoneme (Figs. $17 \& 20)$. Generally, the axoneme was not largely affected, having 9+2 arrangement. The plant extract used to treat this species cause a huge damage to the gonadal tissue surrounding the follicles of the gonads (Fig. 22).

\section{Discussion}

Some authors tested the effect of plant extracts on the reproduction (egg-laying and viability of eggs) and the histological structure of the internal organs of the snails from 
which the hermaphrodites glands (Adewunm et al., 1982; Bakry, 2009a).

One of the ways in which the population of snails could be brought down and there by controlled is to reduce their rate of oviposition by a prolonged exposure to low concentrations of chemical molluscicides (Olivier and Haskins, 1960; Olivier et al., 1962; Cardarelli, 1974; Adewunm et al., 1982).

Bakry (2009a) studied the effect of plant extracts on the hermaphrodite glands of the snail Biomphalaria alexandrina post two weeks of exposure to LC25 of the tested plants. These results showed severe damages in the hermaphrodite glands, obvious degeneration of most gametogenic stages and inhibition of spermatogenesis and oocytes. The same results were recorded by (Rizk, 1998; El-Izzi et al., 1990; Atlam, 2000; Mossalem, 2003).

Rizk (1998) recorded severe changes in the sperms and ova besides degeneration in the gonadal acini structure of $B$. alexandrina snails post exposure to sub-lethal concentrations of the plant Sesbania sesban.

The present study presents for the first time the effect of plant extracts on the ultrastructure of the spermatozoa of the land snails and freshwater snails. For this purpose the fine structure of the spermatozoa of some snails to know the normal structure of them when comparing with the others after treatment with the plant extracts. To confirm this, three species of snails were examined. These snails were the land snail Eobania vermiculata and the two freshwater snails Lymnaea caillaudi and Biomphalaria alexandrina.

It appeared that the extract of Ethulia conyzoides caused severe damage to the gonadal cells in E. vermiculata leading to a great reduction to the number of the spermatozoa inside the hermaphrodite gland. Moreover, the extract of E. milii on $L$. caillaudi and $B$. alexandrina was represented by vacuolation and swelling of the gonadal cells, but the acini of the hermaphrodite glands were noticed filled with the spermatozoa. The nuclei of the spermatozoa of the three snails species become lighter than the normal and the chromatin appeared damaged. Generally, the neck region becomes nearly absent, the glycogen helices have great deformities and the mitochondrial derivative present but not differentiated into layers, while the axoneme was observed normally with its normal structure of 9+2 arrangements of axonemal doublets.

From the above observations on the spermatozoa, it was cleared that the occurrence of gonadal cells damage and the abnormalities viewed in the spermatozoa, give a good idea that the snails which still a live after the exposure period to the plant extracts become nearly sterile. The gonads become unable to produce spermatozoa or the liberated sperms become immotile having damaged mitochondrial derivative and loosed their viability (energy source). Also, the sperms if having some moving forces, they will be unable to complete fertilization due to their nuclear damages. Thus, this effect on sperms can be considered as a new way to control the injurious snails to agriculture and can bring their population down to a low level within a reasonably short period of time.

Concerning that the latex of the plant was demonstrated as one of the most promising molluscicides, minimizing the environmental effects on the limnic ecosystem it can be utilized as an alternative control of the snails as pests and the freshwater snails specially those which are the main intermediate hosts for different helminthic parasites such
Schistosoma, Heterophyes and Fasciola, in agreement with (Mello-Silva, 2006, 2007, 2010).

\section{References}

Adewunmi, C.O., Segun, A.O. and Ashaolu, S.O. (1982) The Effect of Prolonged Administration of Low Concentrations of Bridelia Atroviridis Methanolic Extractive on the Development of Bulinus Globosus. International Journal Of Crude Drug Research 20(3), 101-111.

Al-Daihan, S. (2010) Effect of plant molluscicides on selected enzymes related to energy metabolism in Biomphalaria arabica snails molluscan hosts to Schistosoma mansoni in Saudi Arabia. Journal of the Egyptian Society of Parasitology 40, 187-195.

Atlam, A.E. (2000) Comparative studies on the toxic effect of some plant molluscicides on the target and non-target freshwater snails. PhD Thesis, Faculty of Science, Tanta University, Egypt.

Bakry, F.A. (2009a) Impact of some plant extracts on histological structure and protein patterns of Biomphalaria alexandrina Snails. Global Journal of Molecular Sciences 4, $34-41$.

Cardarelli, N.F. (1974) Slow release molluscicides and related materials. In Molluscicides in Schistosomiasis control (ED.: T.C. Cheng). Academic press, New York, pp. 177-240.

El-Izzi, A., Benie T., Thieulant M. and Duval, J. (1990) Inhibitory effects of saponins from Tetrapleura tetrapleura on the LH release by cultured rat pituitary cells. Planta Medica $56,325-359.107$.

Essawy, A.E., Abdelmeguied, N.E., Radwan, M.A., Hamed, S.S. and Hegazy, A.E. (2009) Neuropathological effect of carbamate molluscicides on the land snail Eobania vermiculata. Cell Biology and Toxicology 25, 275-290.

Kloos, H., De Souza, C., Gazzinelli, A., Soares Filho, B.S. and De Costa, T. (2001) The distribution of Biomphalaria sp. In different hapitats in relation to physical, biological water contact and cognitive factors in a rural area in Minas Gerias, Brazil. Memórias do Instituto Oswaldo Cruz 96, 57-66.

Kristoff, G., Guerrero, N.R.V. and Cochon, A.C. (2010) Inhibition of cholinesterases and carboxylesterases of two invertebrate species, Biomphalaria glabrata and Lumbriculus variegates by the carbamate pesticide carbaryl. Aquatic Toxicology 96, 115-123.

Masola, B., Chibi, M., Naik, Y.S., Kandoare, E. and Zaranyika, M.F. (2003) Activities of glutamate dehydrogenase and alanine amino transferases in fresh water snails Helisoma duryi and Lymnanea natalesis exposed to copper. Biomarkers 8, 33-42.

McCullough, F.S. (1986) Snail control in relation to a strategy for reduction of morbidity due to Schistosomiasis control. Bulletin - World Health Organization 58, 681-689. 
Mello-Silva, C.C., Vasconcellos, M.C., Pinheiro, J. and Rodrigues, M.L.A. (2006) Physiological changes in Biomphalaria glabrata (Say, 1818), (Pulmonata: Planorbidae) caused by sub-lethal concentrations of the latex of Euphorbia splendens var. hislopii N.E.B (Euphorbiaceae). Memórias do Instituto Oswaldo Cruz 101, 1-6.

Mello-Silva, C.C., Vilar, M.M., Bezerra, J.C.B., Vasconcellos, M.C.D., Pinheiro, J. and Rodrigues, M.D.L.D.A. (2007) Reproductive activity alterations on the Biomphalaria glabrata exposed to Euphorbia splendens var. hislopii latex. Memórias do Instituto Oswaldo Cruz 102(6), 671-674.

Mello-Silva, C.C., Vilar, M.M., Vasconcellos, M.C., Pinheiro, J. and Rodrigues, M.D.L.D.A. (2010) Carbohydrate metabolism alterations in Biomphalaria glabrata infected with Schistosoma mansoni and exposed to Euphorbia splendens var. hislopii latex. Memórias do Instituto Oswaldo Cruz 105(4), 492-495.

Mossalem, H.S. (2003) Studies on the molluscicidal and miracidicidal effects of certain wild plants on Schistosoma
mansoni-Biomphalaria alexandrina system. PhD Thesis, Faculty of Science, Ain Shams University, Egypt.

Olivier, L. and Haskins, W.T. (1960) The effects of low concentrations of sodium pentachlorophenate on the fecundity and egg viability of Australorbis glabratus. The American Journal of Tropical Medicine and Hygiene 9, 199-205.

Olivier, L., Haskins, W.T. and Gurian, J. (1962) The action of very low concentrations of sodium pentachlorophenate on freshly laid eggs of Australorbis glabratus. Bulletin of the World Health Organization 27(1), 87-94.

Rashed, A.A. (2002) Biological studies on the snail intermediate hosts of schistosomiasis with a special emphasis on using larval Echinostomes as biocontrol agents against larval schistosomes and snails. Journal of the Egyptian Society of Parasitology 32, 775-784.

Rizk, E.T. (1998) Schistosomiasis control: evaluation of the molluscicidal activity of a plant extract"Sesbania sesban" against Biomphalaria alexandrina. Journal of Egyptian German Society of Zoology 27: 91.

\section{Abbreviations}

A, Acrosome; Ax, axoneme; CF, coarse fibers; DAS, distal accessory sheath; EP, end piece; GG, glycogen granules; GH, glycogen helix; K, keel; MD, mitochondrial derivative; MP, midpiece; $\mathrm{N}$, nucleus; NF, nuclear fossa, Nk neck; PAS, proximal accessory sheath; $\mathrm{pL}$, paracrystalline layers; 

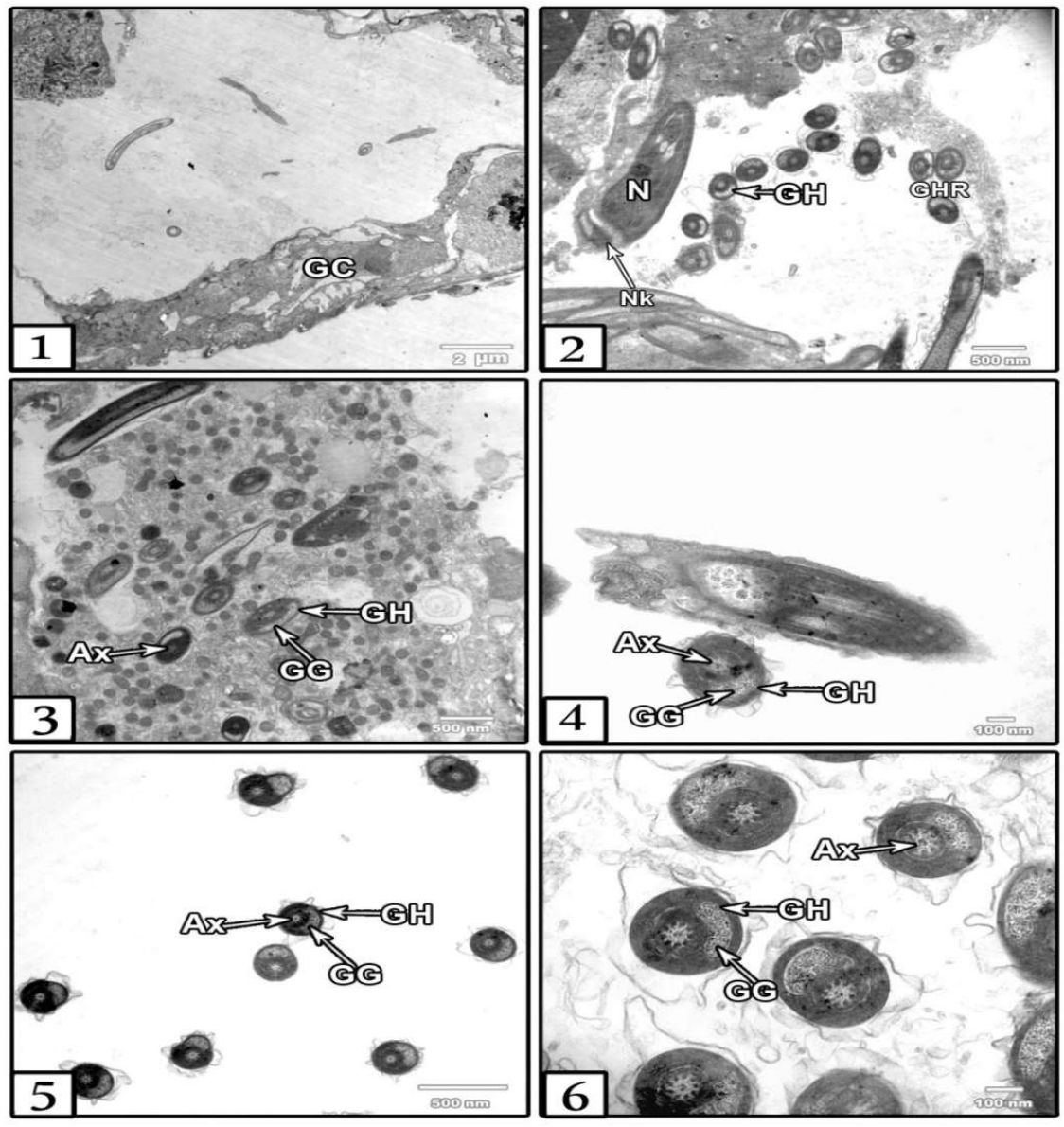

Figs. (1-6): Transmission electron micrographs showing the ultrastructure of the mature spermatozoon of Eobania vermiculata treated with the ethanolic plant extract of Ethulia conyzoides.

Fig. (1): Cross-section through an acinus of gonad revealing a great damage to the genital cells and the lumen of the acinus becomes nearly empty of sperms.

Fig. (2): Transverse sections in some sperms, where the nucleus $(\mathrm{N})$ appeared affected with the extract as it becomes vacuolated and the neck region (Nk) damaged. The glycogen helix region (GHR) appeared not affected.

Fig. (3): Transverse sections in another part of the gonad where a large number of flagella of the sperms without the presence of nuclei. 
Figs. (4-6): Transverse sections in a few sperms through the midpiece revealed that the flagellum of the spermatozoon is largely not affected by the extract. The axoneme (Ax), Paracrystalline layers (PL) of the mitochondrial derivative (MD), the glycogen helix (GH) and the glycogen granules (GG) are normal as in the control.

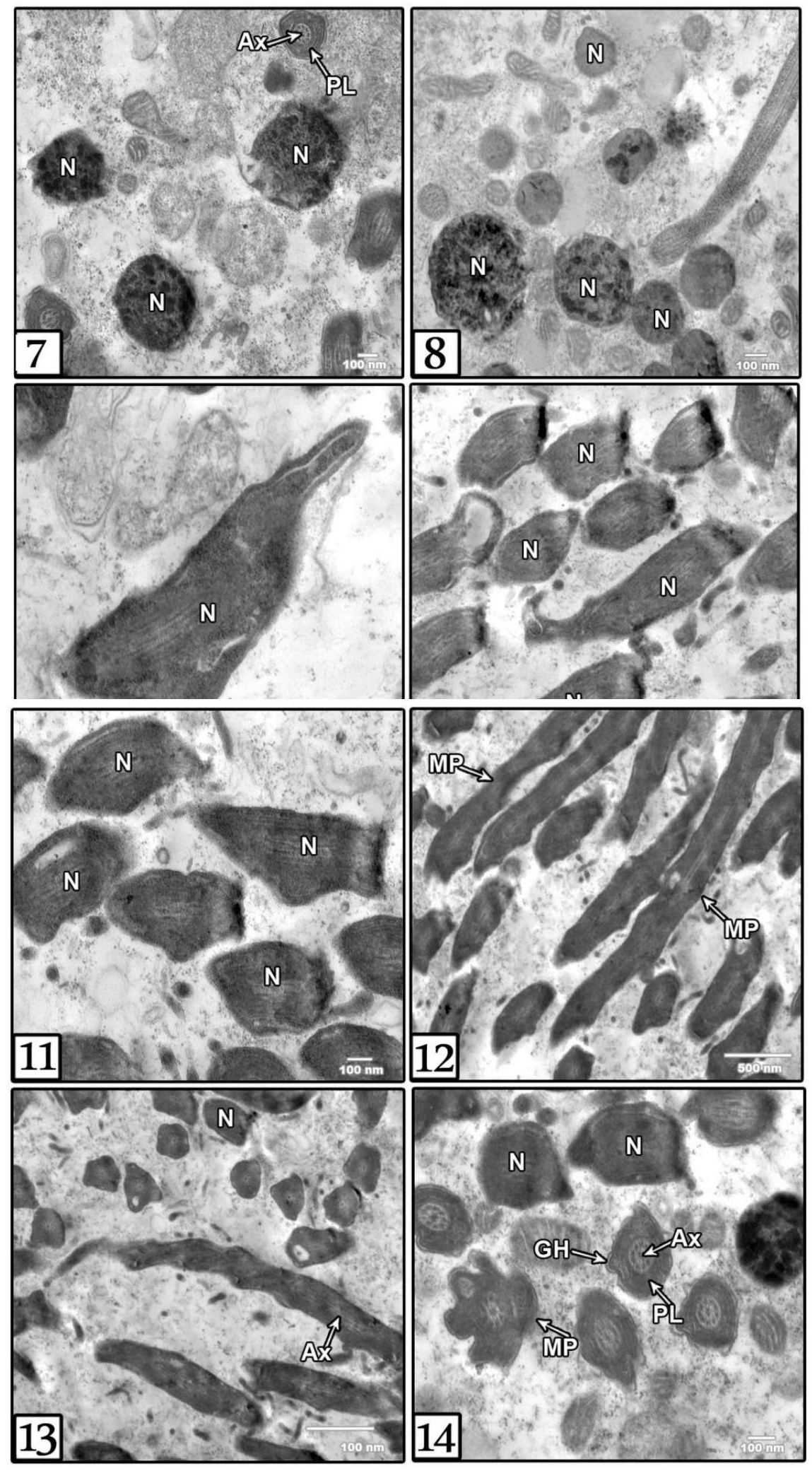


Figs. (7-14): Transmission electron micrographs showing the ultrastructure of the mature spermatozoon of Lymnaea caillaudi treated with the methanolic plant extract of Euphorbia milii.

Figs. (7-11): Longitudinal and transverse sections through the head of the spermatozoon showing the large changes in the nucleus $(\mathrm{N})$. The changes are in the general form and the chromatin material, where there are accumulations in dots or groups or it becomes straight. The helical shape of the nucleus is absent.

Figs. (12-14): Longitudinal and transverse sections through the midpiece revealing large changes or deformities in the glycogen helices $(\mathrm{GH})$, but it seems that the axoneme (Ax) and the paracrystalline layers are less or not affected with the plant extract.
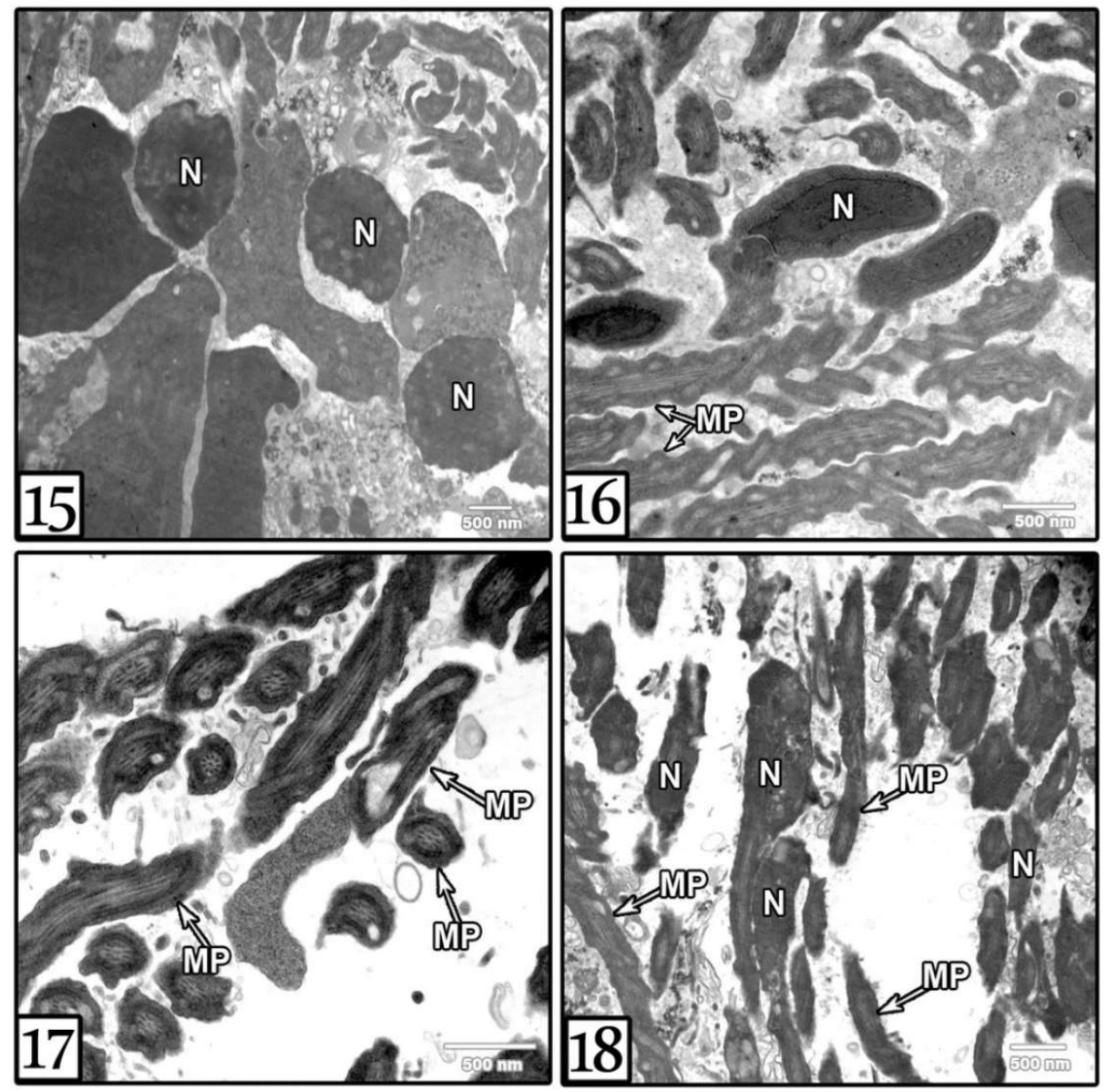


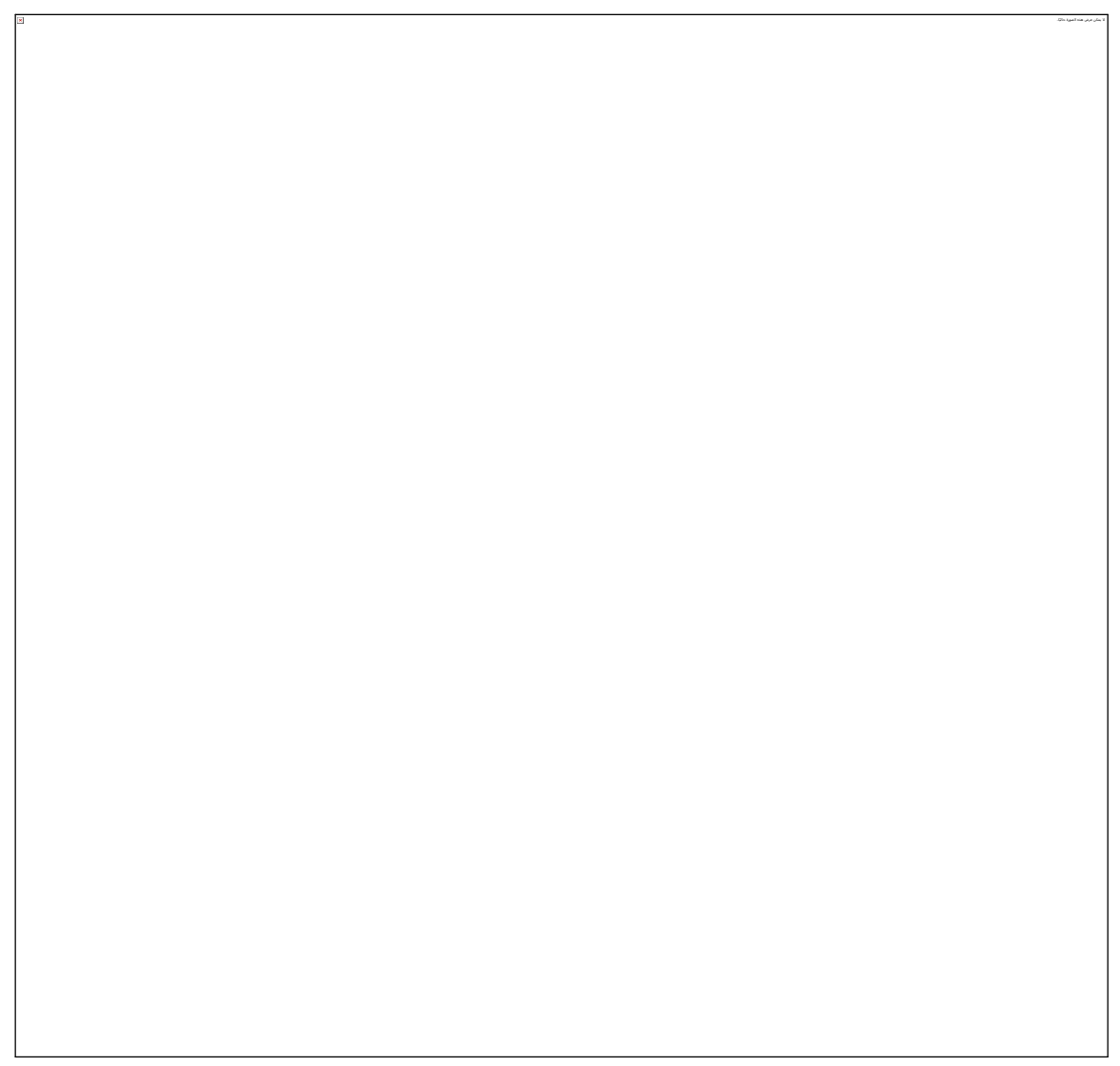

Figs. (15-22): Transmission electron micrographs showing the ultrastructure of the mature spermatozoon of Biomphalaria alexandrina treated with the methanolic extract of Euphorbia milli.

Fig. (15): Longitudinal and transverse sections through the head region showing the nucleus $(\mathrm{N})$, which is largely affected by the extract. The general shape becomes irregular and some nuclei become irregularly elongated. The chromatin material also appeared mostly vacuolated.

Fig. (16): Longitudinal sections showing deformities in the nuclei $(\mathrm{N})$ and with a less degree the midpiece.

Fig. (17): Longitudinal and transverse sections through the midpiece of some sperms where the axoneme $(\mathrm{Ax})$ and the mitochondrial derivative were not affected, while the glycogen helices $(\mathrm{GH})$ appeared loosely affected.

Fig. (18): Longitudinal sections through the midpiece of some sperms markedly affected with the plant extract. 
Fig. (19): Longitudinal sections showing the large effect of the plant extract on the nuclei $(\mathrm{N})$ than on the midpieces of the sperm.

Fig. (20): Cross-sections through the midpiece showing that the axoneme (Ax) is not affected and appeared normal.

Fig. (21): Longitudinal and transverse sections in a large number of the sperms showing the deterioration of the nuclei $(\mathrm{N})$ and with a leaser degree the glycogen helices $(\mathrm{GH})$.

Fig. (22): Apart of the gonadal wall showing the vacuolated cells. Also, cross-sections in the spermatozoa inside the lumen of the acinus, showing the abnormal nuclei $(\mathrm{N})$. 